\title{
An Empirical Analysis of the Efficient Market Hypothesis in China's Stock Market
}

\author{
Jiaxuan $\mathrm{Xu}^{*}$ \\ Jiangnan University, Wuxi 214000, Jiangsu Province, China \\ *Corresponding author: Jiaxuan Xu, 13383578008@163.com
}

\begin{abstract}
The efficient market hypothesis is one of the most important theories in finance. According to this hypothesis, in a stock market with sound laws, good functions, high transparencies, and extensive competitions, all valuable information is timely, accurately, and fully reflected in the trend of stock prices including the current and future values of enterprises. Unless there are market manipulations, it would be impossible for investors to gain more above the average profits in the market by analyzing former prices. Since the efficient market hypothesis has been introduced, it has become an interest in the empirical research of the security market. It is one of the most controversial investment theories and there are many evidences supporting and also opposing this hypothesis. Nevertheless, this hypothesis still holds an important status in the basic framework of mainstream theories in modern financial markets. By analyzing simulated investment transactions in regard to stock trading of three different enterprises, this paper verified that the efficient market hypothesis is partially valid.
\end{abstract}

Keywords: Efficient market hypothesis; Market information; China's stock market

Publication date: June 2021; Online publication: June 30, 2021

\section{Introduction}

The efficient market hypothesis is one of the pillars in the modern stock market system and it is the theoretical foundation of modern financial economics. ${ }^{[1]}$ The efficient market hypothesis (EMH) was first formally proposed by Fama who suggested that in a transparent market, the price of a security would fully, timely, and accurately reflect the market in regard to all new information affecting it. ${ }^{[2]}$ Fama also believes that the financial market is extremely efficient in reflecting information. ${ }^{[3]}$ However, there are different views on EMH in the academic circle. As a matured financial and economic theory, EMH is challenged by market anomalies and behavioral finance since it was proposed. For example, Su and Xing stated that abnormal phenomenon that contradicts the efficient market theory have been constantly emerging in the financial market since the $1980 \mathrm{~s} .{ }^{[4]}$ Ding also argued that the efficient market hypothesis is unrelated to the real stock market. ${ }^{[5]}$

This paper hypothesized that market information is partly effective in the application of the efficient market hypothesis in China's stock market. Three stocks portfolios were selected and simulated investment transactions in regard to stock trading were carried out to analyze and for clear demonstration in validating the hypothesis. The information of the stocks is shown in Table 1.

Table 1.

\begin{tabular}{|c|c|c|c|}
\hline Stock Code & Stock Name & Positions (\%) & Profit and loss (\%) \\
\hline 000651 & Gree Electric Appliances & 23.50 & -4.75 \\
\hline 600000 & Shanghai Pudong Development Bank & 11.74 & -5.73 \\
\hline 002353 & Yantai Jereh Oilfield Services Group & 9.90 & 2.30 \\
\hline
\end{tabular}




\section{Empirical Analysis}

\subsection{Market effectiveness analysis of Gree Electric Appliances}

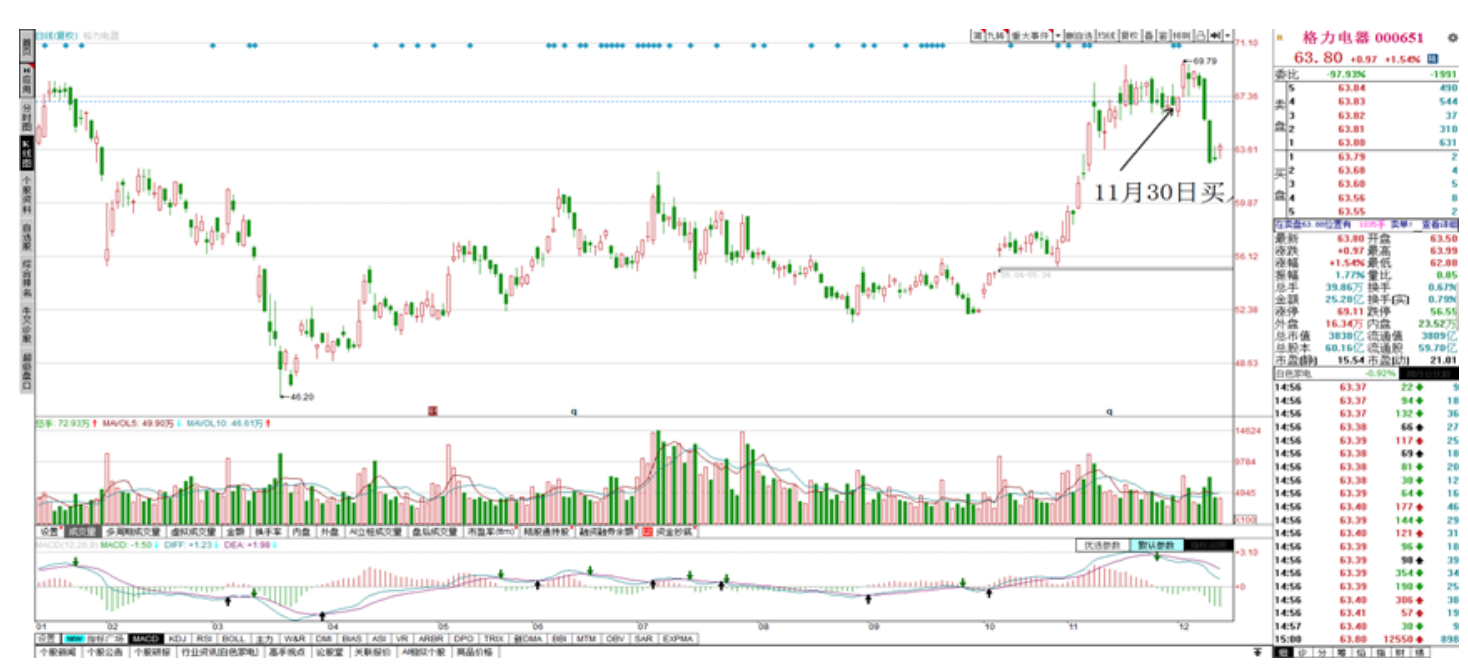

Figure 1.

Figure 1 shows the daily K-Line trend of Gree Electric Appliances (000651) from the beginning of January to December 13 . The buying time was on November 30 in the simulated stock market.

\subsubsection{Supporting evidence}

The market information of Gree to repurchase stocks were valid in which the movements of the stock prices fully reflected them. In order to further analyze the market effectiveness, historical public information on Gree were examined. On April 10, Gree announced their share repurchase plan. The total amount of share repurchase funds was between three to six billion yuan and the share repurchase price was no more than $¥ 68.8$ per share. After the announcement of the company’s repurchase plan, the share price was no longer below $¥ 49.68$ per share. This indicated that Gree’s historical public information have been fully reflected in the trend of share prices, thereby proving the effectiveness of market information.

In the perspective of trading volume, in early October 2020, Gree announced that their share repurchase plan had achieved 5.182 billion yuan. After the announcement, Gree began a new round of volume rise in October and the trading volume was significantly increased indicating that the market trend fully reflects the company's public information, and the market was efficient.

\subsubsection{Opposing evidence}

The third quarter results fell but Gree's share prices rose which meant market information was ineffective. At the end of October, Gree announced its third quarter performance with operating income of 125.889 billion yuan and was down $18.80 \%$ on a year-over-year basis. After the release of the third quarter report, the stock prices of the company began a new round of volume rise. Under the circumstance of declining performance, the prices of shares rose instead of dropping. The figures bared no relationship to the overall company performance and indicated a market dysfunction of ineffective resource allocation. The market trend did not reflect the real financial information of the company. 


\subsection{Market effectiveness analysis of Shanghai Pudong Development Bank}

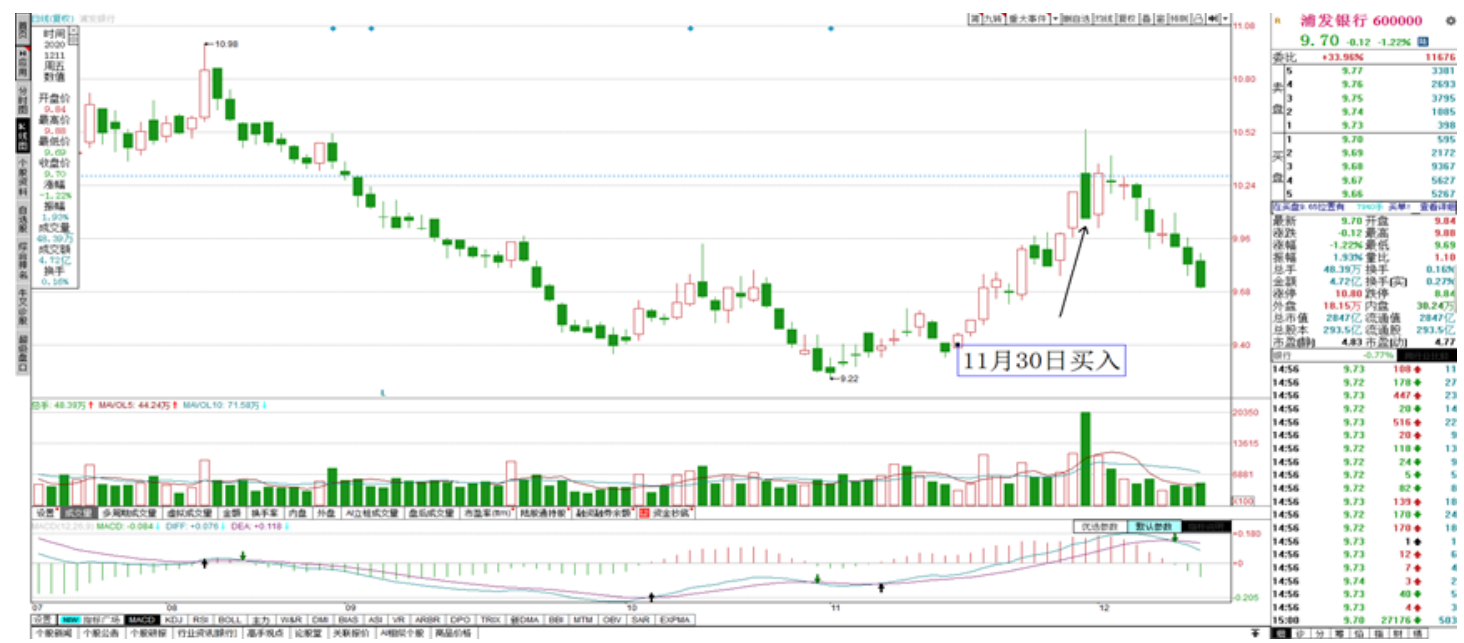

Figure 2.

Figure 2 shows the daily K-Line trend of Shanghai Pudong Development Bank (600000). The buying time was also on November 30 in the simulated stock market.

\subsubsection{Supporting evidence}

The business information was effective in short-term. On the $26^{\text {th }}$ of November, The China Business Network reported news pertaining Shanghai Pudong development bank (SPD Bank) that formed a specialized network from the start-up to the maturity of enterprises. It was mentioned that the bank was able to support the whole process, cycle, as well as the market of intelligent service plan. The third quarter report showed that the numbers of technology service enterprises of the company were 38,000 with a yearover-year growth of $7.73 \%$ and an increased in credit supply by $27.6 \%$. From this information, the development situation of SPD Bank was relatively good. After the release of the information, the shares rose for two consecutive days in small amounts. Hence, the short-term market reflected the business information of SPD Bank which indicated that the market was effective.

\subsubsection{Opposing evidence}

The business information portrayed good operation qualities, but the company's share prices continued to fall in a volatile manner after a short rise. This indicated that the effectiveness of the market information was weak. Being optimistic about SPD Bank's operation qualities, their stocks were bought at the opening, which was on Monday, November 30. However, after the purchase, the prices of shares fell back on the day itself with a large trading volume. Thereafter, the stock prices have been in a negative decline state. The business information provided involved the fundamentals of the company, thereby the stock prices should have rose in long-term. However, the prices of shares fell back which meant that the market effectiveness of SPD Bank's operation information was weak. 


\subsection{Market effectiveness analysis of Yantai Jereh Oilfield Services Group}

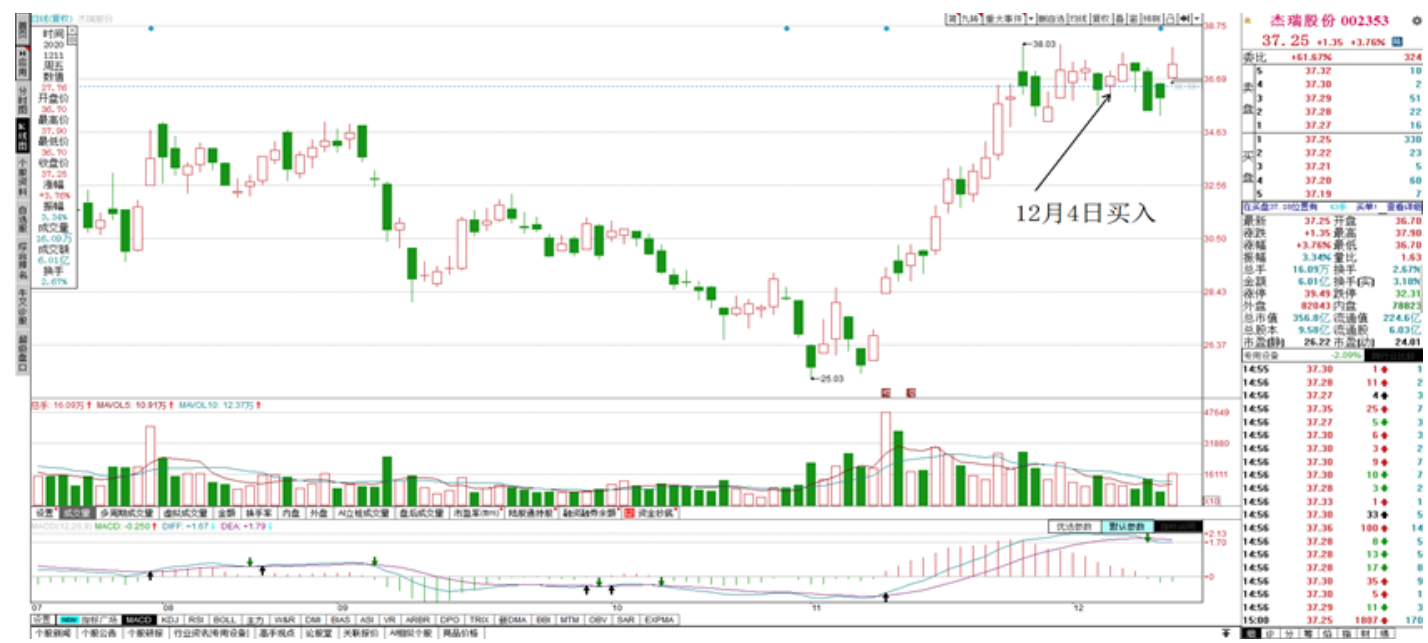

Figure 3.

Figure 3 shows the daily K-Line trend of Yantai Jereh Oilfield Services Group (002353). The buying time was on the $4^{\text {th }}$ of December in the simulated stock market.

\subsubsection{Supporting evidence}

After the announcement of Pfizer's vaccine, the prices of engineering and construction-related shares rose. This indicated that the market information was effective. On November 10, Pfizer announced that their COVID-19 vaccine was successfully developed. Global oil prices responded quickly and the boom in oil and gas service-related industries were expected to reverse. As an industry leader in the oil and gas field engineering equipment, Jereh's shares surged $8.43 \%$ in volume on November 10 , and recently, the stock price continued to rise reflecting the effectiveness of Pfizer's vaccine information.

After the buying of Jereh's shares on December 4, the market share prices continued to rise after a short period of volatility. This upward trend reflected the positive performance information in the third quarter and the news regarding COVID-19 vaccine.

\subsubsection{Opposing evidence}

The third quarter was good, but the stock price fell for two days indicating that market information was ineffective. Jereh's stock announced their performance report on October 29 in which the third quarter revenue was 5.424 billion yuan with a year-over-year growth of $27.91 \%$ while the net profit was 1.115 billion yuan with a year-over-year growth of $23.18 \%$. During the epidemic, the company's performance was good. However, after the release of the information, Jereh's shares plunged for two trading days which indicated that the trend of the stock prices did not reflect the company's performance information; hence, proving that the market information was invalid.

\section{Conclusion}

By analyzing the simulated investment transactions of three stocks portfolios belonging to Gree Electric Appliances, Shanghai Pudong Development Bank, and Yantai Jereh Oilfield Services Group, a conclusion is drawn in which the efficient market hypothesis is partly verified. Stock prices may accurately reflect historical information but not necessarily insider information or the information made public by the company. Figure 4 shows the summary of the market effectiveness reflected by the three stocks. 


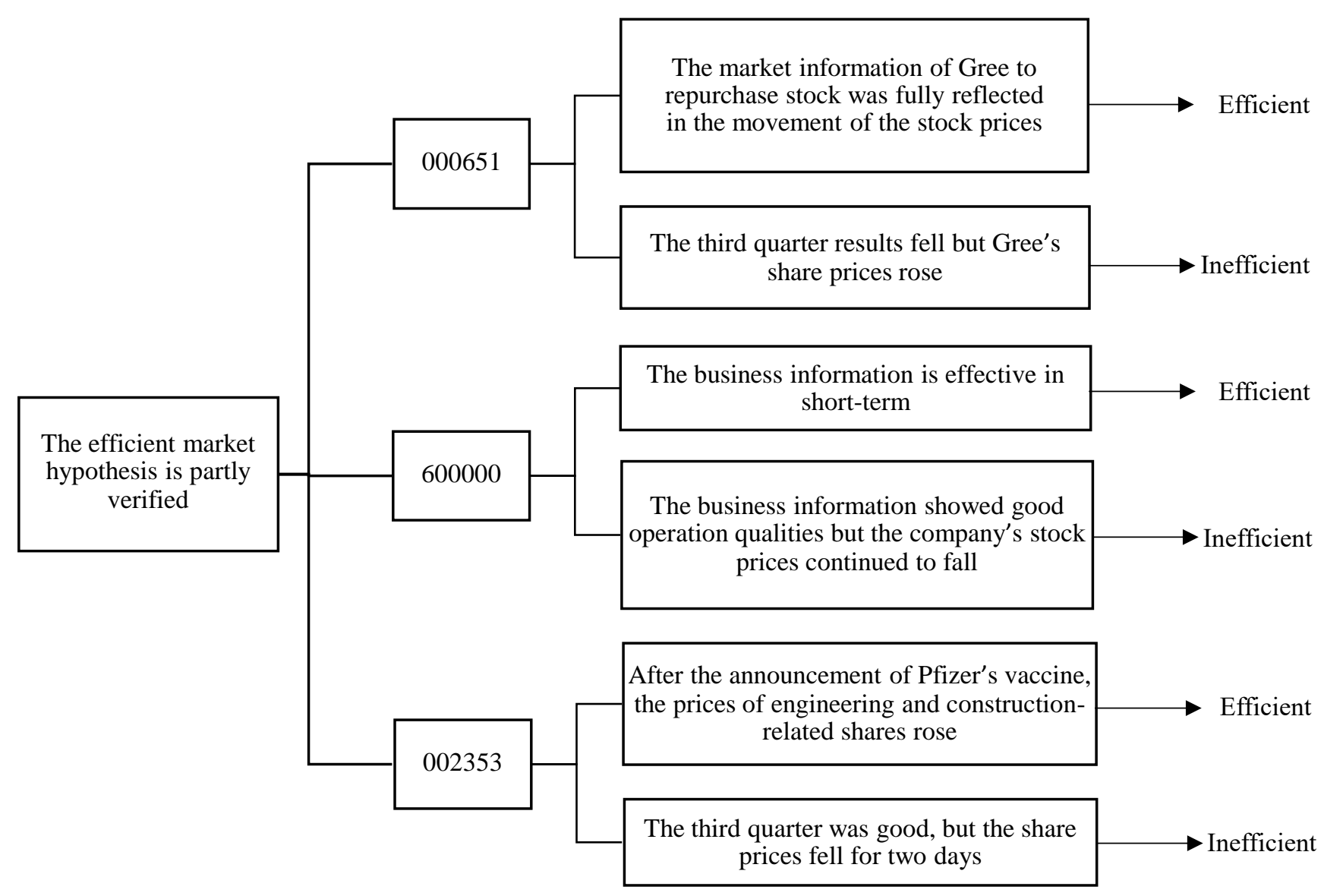

Figure 4.

\section{Disclosure statement}

The author declares no conflict of interest.

\section{References}

[1] Wang NN, 2011, The capital market efficient market hypothesis and its criticism. Kaoshi Zhoukan, 000(023): 235-237.

[2] Fama EF, 1970, Efficient capital market: a review of theory and empirical work. Journal of Finance, 25: $383-417$.

[3] Fama EF, 1998, Market efficient, long-term returns, and behavioral finance. Journal of Financial Economics, 49: 283-306.

[4] Su YH, Xing QC, 2007, Behavioral finance theory: reconsideration of the effective market hypothesis. Finance \& Economics, : 1000-8306.

[5] Ding ZG, Jin B, Xu DC, 2017, The test of efficient market - criticism of EMH theory by behavioral finance. Contemporary Economic Research, :1005-2674. 